\title{
Association of Human Cytomegalovirus Infection with Different Forms of Diabetes
}

\author{
Chatterjee A and Chakraborty $\mathrm{N}^{*}$ \\ Virus Research Laboratory, ICMR-NICED, Kolkata, India
}

ISSN: 2578-0263

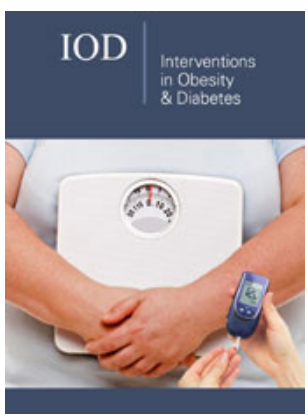

*Corresponding author: Nilanjan Chakraborty, Virus Research Laboratory, ICMR-NICED, Kolkata, India

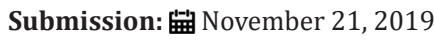

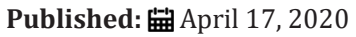

Volume 4 - Issue 1

How to cite this article: Chatterjee $A$ Chakraborty N. Association of Human Cytomegalovirus Infection with Different Forms of Diabetes. Interventions Obes Diabetes 4(1). IOD.000576. 2020. DOI: $10.31031 /$ IOD.2020.04.000576

Copyright@ Chakraborty N. This article is distributed under the terms of the Creative Commons Attribution 4.0 International License, which permits unrestricted use and redistribution provided that the original author and source are credited.

\begin{abstract}
Different forms of virus induced infections are related to the enlarged risk of diabetogenic diseases in humans. Human cytomegalovirus infection has been advised by multiple studies to be one amongst the causative agents. HCMV infection has been linked to the development of both type 1 and type 2 diabetes as well as post-transplantation diabetes. The limited amount of available data indicates that active HCMV infection increases the risk of diabetes by either inhibiting the release of insulin from pancreatic cells or specifically destructing the pancreatic $\beta$ cells. The mechanism is mainly attributed to the expression of pro-inflammatory cytokines that eventually results in programmed cell death or critical disturbances to the functioning of the $\beta$-cells.
\end{abstract}

Keywords: Human cytomegalovirus; Type 1 and type 2 diabetes; Cytokines; Pancreatic $\beta$ cell

\section{Introduction}

The incidence of diabetes is rising at a considerable rate throughout the world, and this may be due to many factors that can directly or indirectly participate in the etiology of the disease. These factors mainly include obesity, autoimmunity diseases, genetic factors and infection [1]. Many viruses have been reported to infect humans and causing diabetes through different processes such as hepatitis or pancreatitis and their associated complications [1]. Human Cytomegalovirus [HCMV] is considered to be one of the most important viruses that is thought to be a causative agent of type I diabetes due to its ability for inducing damage to the immunological beta cells ( $\beta$-cells) [2]. HCMV is a widely distributed virus, belonging to betaherpesvirinae subfamily, capable of infecting a vast range of cell types, including adipocytes, monocytes and endothelial cells, and it is never entirely cleared by the immune system, resulting in a latently persistent infection [2]. While HCMV represents a critical threat to both newborns and immunocompromized or immunosuppressed individuals, infection in the immunocompetent typically remains asymptomatic in nature [3]. Latent infection in otherwise healthy individuals still results in regular subclinical reactivation of the virus, requiring adequate and sustained type 1 T-cell host responses to repeatedly suppress viral replication as well as dissemination. Human cytomegalovirus [HCMV] has been shown to contribute to $\beta$ cell dysfunction in new-onset type 1 diabetes mellitus [3]. Previous studies reported a significant association between high titre of anti-cytomegalovirus and anti-islet cell antibodies and also showed that asymptomatic cytomegalovirus infection is associated with increased risk of new-onset type I diabetes and impaired insulin release after renal transplantation [2,3]. Another independent study revealed that the HCMV seropositivity is significantly associated with various indicators of glucose regulation and therefore HCMV infection might be a risk factor for the development of type 2 diabetes in the elderly [4]. Other studies have found a significant collinearity of trends between diabetes, seropositivity to HCMV, and age. The findings indicated an up to 12 fold greater odds of having type 2 diabetes for persons previously exposed to HCMV [4]. This review very briefly highlights the association between HCMV infection and the development of diabetes, alongside focusing on the immunological attributes behind this association.

\section{Immunology of Disease}

HCMV has the ability to induce immunological $\beta$ cell destruction [5]. This characteristic destruction is mainly mediated by utilizing the principal immunological mechanism of molecular mimicry. This mimicry could be involved in cytomegalovirus-induced diabetes by 
inducing islet $\beta$ cell autoantibodies $[4,5]$ or extensive loss of selftolerance. The loss of T-cell tolerance to self may be attributed to the presentation or processing of molecularly mimic cytomegalovirus protein pUL57 by dendritic cells. HCMV is also involved in accelerating pancreatic failure to compensate for insulin resistance via two possible mechanisms [6]. Firstly, it could influence the pancreatic cells directly; secondly, it might act indirectly by influencing the immune system, which in turn affects the pancreas [7]. This is consistent with the first possibility which reported that HCMV may infect and reside in pancreatic cells without causing cytopathic effects but nonetheless influencing insulin production directly after repeated reactivations. Additionally, infection of human pancreatic $\beta$-cells with HCMV induces the release of proinflammatory cytokines and increased cellular immunogenicity [8]. The indirect effects of HCMV could be exerted via infected monocyte production of IL- $1 \beta$ which induces TNF- $\alpha$ production in human pancreatic duct cells, driving cells into apoptosis and thus compromising $\beta$-cell function. HCMV seropositivity is also associated with accumulations of potentially senescent late differentiated T-cells and elevated numbers of CD4+ and CD8+ effector cells, which are more likely to produce pro-inflammatory cytokines [9].

\section{Conclusion}

Human pancreatic $\beta$ cells are highly susceptible to HCMV infection and replication [9]. The infection has massive immunologic consequences, as demonstrated by an extensive release of proinflammatory cytokines as well as a rapid increase in the cellular immunogenicity [10]. The increased cellular immunogenicity may enhance the intrinsic capacity of pancreatic $\beta$ cells to activate T cells, making HCMV-infected $\beta$ cells even more vulnarable to immune cells mediated destruction [11]. It has been demonstrated that parts of the $\beta$-cell response to HCMV are due to binding of the virus to the beta cells or cellular entry only, mediated with binding to Intracellular Cell adhesion Molecule 1 [ICAM-1] and release of different proinflammatory cytokines, whereas in some cases, regulation is dependent on viral replication [12]. More active studies with larger patient groups and longer time periods are needed to understand all the perspectives associated with this association.

\section{References}

1. Aarnisalo J, Veijola R, Vainionpää R, Simell O, Knip M, et al. (2008) Cytomegalovirus infection in early infancy: risk of induction and progression of autoimmunity associated with type 1 diabetes. Diabetologia 51(5): 769-772.

2. Elhawary E, Mahmoud GF, El Daly MA, Mekky FA, Esmat GG, et al. (2011) Association of HCV with diabetes mellitus: An Egyptian case-control study. Virol J 8: 367.

3. Yoo SG, Han KD, Lee KH, La Y, Kwon DE, et al. (2019) Impact of cytomegalovirus disease on new-onset type 2 diabetes mellitus: population-based matched case-control cohort study. Diabetes Metab J 43(6): 815-829.

4. Guo T, Jia H (1998) Epidemiologic study of cytomegalovirus infection in patients with diabetes mellitus. Zhonghua Liu Xing Bing Xue Za Zhi 19(5): 274-276.

5. Hiltunen M, Hyty H, Karjalainen J, Leinikki P, Knip M, et al. (1995) Serological evaluation of the role of cytomegalovirus in the pathogenesis of IDDM: A prospective study. Diabetologia 38(6): 705-710.

6. Liang $\mathrm{H}$, Liang $\mathrm{YZ}$, Chen $\mathrm{H}, \mathrm{Yu} \mathrm{ZQ}$ Su JH, et al. (2003) Role of cytomegalovirus infection in the pathogenesis of type 2 diabetes mellitus. Zhonghua Shi Yan He Lin Chuang Bing Du Xue Za Zhi 17(4): 351-353.

7. Dworzański J, Drop B, Kliszczewska E, Dudziak MS, Dacewicz MP (2019) Prevalence of epstein-barr virus, human papillomavirus, cytomegalovirus and herpes simplex virus type 1 in patients with diabetes mellitus type 2 in South-Eastern Poland. PLoS ONE 14(9): e0222607.

8. Hjelmesaeth J, Sagedal S, Hartmann A, Rollage H, Egeland T, et al. (2004) Asymptomatic cytomegalovirus infection is associated with increased risk of new-onset diabetes mellitus and impaired insulin release after renal transplantation. Diabetologia 47(9): 1550-1556.

9. Smelt MJ, Faas MM, de Haan B, Draijer C, Hugenholtz GCG, et al. (2012) Susceptibility of human pancreatic beta cells for cytomegalovirus infection and the effects on cellular immunogenicity. PANCREAS 41(1): 39-49.

10. Esser N, Legrand Poels S, Piette J, Scheen AJ, Paquot N (2014) Inflammation as a link between obesity, metabolic syndrome and 2 diabetes. Diabetes Res Clin Pract 105(2): 141-150.

11. Zhang J, Liu YY, Sun HL, Li S, Xiong HR, et al. (2015) High human cytomegalovirus IgG level is associated with increased incidence of diabetic atherosclerosis in type 2 diabetes mellitus patients. Med Sci Monit 21: 4102-4110.

12. Grossmann V, Schmitt VH, Zeller T, Panova Noeva M, Schulz A, et al. (2015) Profile of the immune and inflammatory response in individuals with prediabetes and type 2 diabetes. Diabetes Care 38(7): 1356-1364. 